\title{
IMPLEMENTASI LEFT CORNER PARSING UNTUK PEMBELAJARAN GRAMMAR BAHASA INGGRIS PADA GAME 3D ADVENTURE “GO TO LONDON"
}

\author{
Fachry Khusaini, Fachrul Kurniawan \\ Jurusan teknik Informatika ${ }^{1,2}$, Fakultas Sains dan Teknologi, UIN Maulana Malik \\ Ibrahim Malang \\ E-mail: fachry137@gmail.com, fach_77@yahoo.com
}

\begin{abstract}
ABSTRAK
Bahasa Inggris adalah bahasa internasional yang digunakan seluruh orang di dunia untuk berinteraksi satu sama lain. Mempelajari bahasa Inggris sangat diperlukan pada saat ini. Banyak metode pembelajaran yang digunakan untuk mempelajari bahasa Inggris. Game merupakan media pembelajaran yang menyenangkan, terutama bagi anak. Melalui game, anak dapat belajar sambil bermain dalam mengembangkan kemampuannya. Game yang dibangun adalah game pembelajaran grammar bahasa Inggris menggunakan algoritma left corner parsing sebagai pemeriksa dalam kalimat yang dibuat.Algoritma yang digunakan dalam memeriksa sebuah kalimat sangat banyak macamnya, salah satunya algoritma left corner parsing. Algoritma left corner parsing merupakan gabungan dari dua algoritma, yaitu algoritma top down parsing dan bottom up parsing. Tugas algoritma ini memeriksa setiap kata dalam sebuah kalimat, kemudian mencocokkan sebuah pola grammar terhadap hasil pemeriksaan tersebut. Proses pemeriksaan ini yang akan menjadi pemeriksa kata dalam game. Dari uji coba yang dilakukan, metode left corner parsing dapat mengenali pola grammar dengan sangat baik, akan tetapi dalam mengenali makna untuk membentuk sebuah kalimat yang benar masih menjadi kekurangan.
\end{abstract}

Kata kunci:Bahasa Inggris, Game, Left Corner Parsing, Gramm

\section{PENDAHULUAN}

\subsection{LATAR BELAKANG}

Bahasa Inggris adalah salah satu dari banyak macam bahasa yang digunakan. Bahasa Inggris sering digunakan dikarenakan bahasa Inggris adalah bahasa internasional yang digunakan oleh banyak negara di dunia untuk berkomunikasi. Dahulu begitu banyak invasi negara Inggris terhadap negara-negara lain, dan akhirnya bahasa inggris diakui sebagai bahasa internasional (Priyana, 2013).

Negara Indonesia dalam hal bahasa Inggris sudah mulai dipelajari dari tingkat sekolah dasar (SD). Dimulai dari bagaimana cara menulis yang benar, lalu kemudian berlanjut dengan cara pengucapannya yang benar. Dalam faktanya walaupun bahasa Inggris sudah dipelajari dari SD, akan tetapi masih banyak juga yang kurang memahami bagaimana cara pengucapan bahasa Inggris dan juga penulisannya. Bahkan yang sudah menjadi guru/pengajar pun belum tentu bisa dalam hal menulis ataupun mengucapkan bahasa Inggris dengan benar.

Dalam pembelajaran bahasa Inggris terdapat sebuah tata bahasa yang digunakan sebagai standar untuk mengetahui bahasa yang digunakan itu sudah benar atau belum. Standar yang digunakan biasa disebut grammar. Di 
dalam grammar terdapat beberapa cara atau metode untuk menyusun sebuah kalimat dalam membuat sebuah cerita atau untuk berkomunikasi dengan orang lain dengan benar. Dengan mempelajari grammar dengan baik dan benar akan menghasilkan sebuah pemahaman tentang struktur bahasa inggris yang baik dan benar. Dari permasalahan pemahaman grammar ini muncullah ide untuk membuat sebuah pembelajaran tentang grammar bahasa Inggris dimulai dari anak usia dini melalui game adventure "Go to London" yang akan dibangun.

\subsection{RUMUSAN MASALAH}

Dari pemaparan latar belakang di atas, perumusan masalah dalam penelitian ini, yaitu bagaimana menerapkan algoritma left corner parsing sebagai pemeriksa grammar bahasa Inggris di dalam sebuah game adventure "Go to London"?

\subsection{BATASAN MASALAH}

Agar tujuan lebih terarah dengan jelas dan sistematis, maka permasalahan kami batasi sebagai berikut:

1) Game yang dibangun berjenis game adventure.

2) Game bersifat single player.

3) Game engine yang digunakan adalah 3D Game Studio A8.

4) Bahasa pemrograman yang digunakan adalah Lite-C.

5) Algoritma yang digunakan adalah Left Corner Parsing.

6) Bentuk kalimat yang digunakan dalam game yaitu positif tidak termasuk kalimat pertanyaan.

7) Game ini untuk anak-anak usia 813 tahun.

8) Kalimat yang digunakan di dalam game menggunakan kalimat sederhana.

9) Setiap kata dianggap hanya memiliki satu arti untuk menghindari ambigu yang terjadi dalam pemilihan tipe atau jenis dari kata tersebut.
10) Kalimat tidak mengandung preposition atau to be yang disingkat seperti " $i$ ' $m$ " yang seharusnya "I am".

11) Tense yang digunakan yaitu simple present tense, simple past tense, dan simple future tense.

12) Pemeriksaan dilakukan pada pola kalimat.

\subsection{TUJUAN DAN}

\section{MANFAAT}

Penelitian ini bertujuan untuk menerapkan algoritma left corner parsing sebagai pemeriksa kalimat pada game 3D "Go to London" adventure.

Manfaat dari game ini adalah untuk mempermudah anak dalam mempelajari bahasa Inggris dari segi grammar. Pembuatan game ini dapat membantu mengenali pola grammar sebelum membuat sebuah kalimat bahasa Inggris yang sesuai dengan aturan grammar.

\section{DASAR TEORI}

\subsection{BAHASA INGGRIS}

Bahasa Inggris adalah sebuah bahasa yang berasal dari Inggris. Bahasa ini menjadi bahasa utama di daerah Britania Raya (Irlandia, Wales, serta Inggris), Amerika Serikat dan banyak negara yang menggunakannya (Hidayat, 2006).

Di dalam sebuah bahasa pasti terdapat struktur dalam pembuatan sebuah kalimat yang nantinya akan dituliskan atau dikomunikasikan oleh seseorang. Di bahasa Inggris lebih diketahui sebagai grammar atau tata bahasa. Di dunia saat ini yang menjadi pedoman dalam penggunaan grammar yaitu grammar dari Amerika dan Inggris. Kalimat dalam tata bahasa Inggris memiliki pola tertentu yang digunakan untuk membentuk sebuah kalimat. Jenis kata yang terdapat di dalam bahasa Inggris ada 24 macam (Nina, 2010), yaitu:

1. Articles (Kata Sandang)

2. Auxiliary Verb (Kata Kerja Bantu) 
3. Verbs (Kata Kerja)

4. Nouns (Kata Benda)

5. Adjectives (Kata Sifat)

6. Adverbs (Kata Keterangan)

7. Posesive Forms (Bentuk Kepemilikan)

8. It and There (Bentuk It Dan There)

9. Modal Auxiliaries (Kata Kerja Bantu)

10. Pronouns (Kata Ganti)

11. Preposition (Kata Depan)

12. Conjuctions (Kata Sambung)

13. Infinitive (Bentuk Dasar Kata Kerja)

14. Question Words Questions (Kata Tanya)

15. Participles (Kata Kerja Partisipatif)

16. Question Tag (Pertanyaan Penegas)

17. Gerunds (Kata Kerja -Ing)

18. Conditional Sentences (Kalimat Pengandaian)

19. Active And Pasive Voice (Kalimat Aktif Dan Pasif)

20. Agreement/Concord (Persesuaian)

21. Phrases And Clauses (Frase Dan Klausa)

22. Direct And Indirect Speech (Kalimat Langsung Dan Tak Langsung)

23. Iregular Verb (Kata Kerja Tak Berurutan)

24. Tenses (Bentuk-Bentuk Waktu)

Sistem kala atau waktu dalam bahasa Inggris dinamakan tense. Tense terdiri dari tiga wilayah tense yaitu: Past Tense (waktu lampau), Present Tense (waktu sekarang), serta Future Tense (waktu akan datang). Dalam setiap tense dikembangkan menjadi empat yaitu Simple, Continuous, Perfect, Perfect Continuous, terkecuali Future Tense yang memiliki delapan macam yang telah dikembangkan. (Winarno, 2006)

\subsection{GRAMMAR}

Grammar di dalam kamus bahasa Inggris memiliki arti tata bahasa. Secara definisi umum grammar adalah aturan-aturan pembentukan suatu kalimat dalam bahasa, atau biasa juga disebut tata bahasa.

Dengan adanya grammar, proses parsing dapat dilakukan secara cepat dengan cara mencocokkan aturanaturan yang tepat untuk membentuk struktur suatu kalimat (Suciadi, 2001).

Salah satu contoh grammar sederhana untuk bahasa Inggris ialah sebagai berikut:

a) Sentence $=$ noun phrase + verb phrase

b) Noun phrase $=$ determiner + noun

c) Verb phrase $=$ verb + noun phrase

d) Determiner $=$ the,$a$

e) Noun $=d o g$, dogs, cat

f) Verb = chased, see, sees

Dari grammar diatas dapat dibentuk beberapa kalimat bahasa Inggris yang sederhana, yaitu:

a) The dog chased a cat

b) The dog sees a cat

Proses pembentukan kalimat "The dog chased a cat" dari grammar tersebut dapat dilihat pada Gambar 1 .

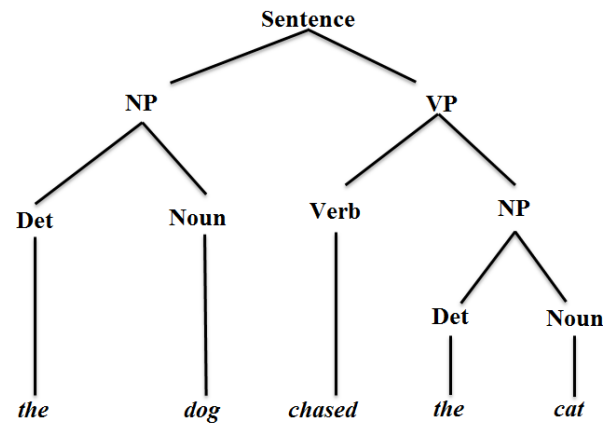

Gambar 1. Parse tree

\subsection{PARSING}

Parsing adalah proses menentukan apakah sekumpulan string yang dibuat di token dapat dibuat oleh sebuah grammar. Parser ini nantinya 
diharapkan dapat mengirimkan kesalahan yang terdapat dalam sintaks bahasa tersebut serta mengecek apakah sebuah kalimat tersebut benar sesuai grammar atau tidak.

Ada tiga parser yang biasa digunakan untuk sebuah grammar yaitu Top Down Parsing, Bottom Up Parsing, serta gabungan dari keduanya Left Corner Parsing. Left Corner Parsing pertama kali dikemukakan oleh Rosenkrantz dan Lewis II pada tahun 1970. LC (Left Corner) parsing merupakan strategi yang menggunakan data secara bottom up parsing dan prediksi dari top down parsing.

\subsection{LEFT CORNER PARSING}

Left Corner Parsing adalah gabungan dari dua buah metode yaitu Top-Down dan Bottom-Up Parsing. Top-Down Parsing melakukan penelusuran dari root/puncak menuju ke leaf/daun (simbol awal sampai simbol terminal). Top-Down bekerja dengan cara menguraikan sebuah kalimat mulai dari constituent yang terbesar sampai menjadi constituent yang terkecil. Constiuent sendiri yaitu unsur-unsur pembentuk kalimat yang dapat berdiri sendiri seperti noun, dan verb. Hal ini dilakukan terus-menerus sampai semua komponen yang dihasilkan ialah constituent yang terkecil dalam kalimat, yaitu kata.

Sedangkan Bottom-Up Parsing bekerja dengan cara mengambil satu demi satu kata dari kalimat yang diberikan, untuk dirangkaikan menjadi constituent yang lebih besar. Hal ini dilakukan terus-menerus sampai constituent yang terbentuk ialah sentence atau kalimat. Dengan demikian metode Bottom-Up Parsing ini bekerja dengan cara yang terbalik dari cara kerja Top-Down Parsing.

Cara kerja Left Corner Parsing ialah dengan mula-mula menerima sebuah kata, menentukan jenis constituent apa yang dimulai dengan jenis kata tersebut, kemudian melakukan proses parsing terhadap sisa-sisa constituent tersebut dengan cara Top Down. Dengan demikian proses Left-Corner Parsing dimulai secara Bottom Up dan diakhiri secara Top Down (Suciadi, 2001)

Berikut adalah proses cara kerja dari Left Corner Parsing dalam Gambar 2.

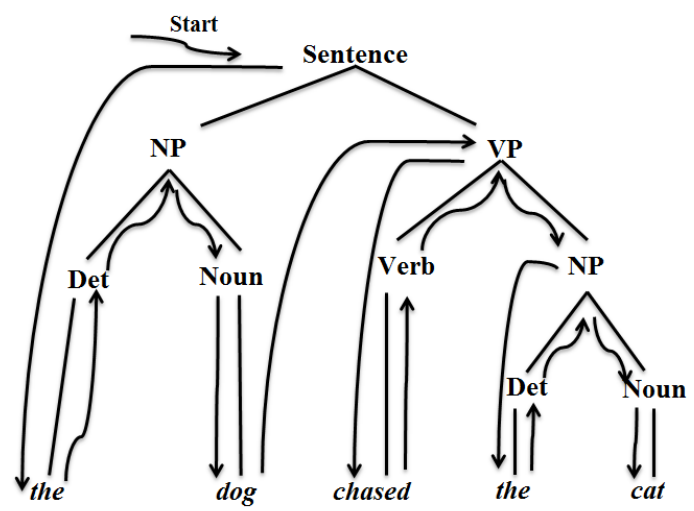

Gambar 2. Left Corner Parsing

\section{RANCANGAN DESAIN SISTEM}

\subsection{STORY BOARD}

Dalam subbab ini menjelaskan Gambaran rancangan game yang akan dibuat. Dimulai dengan sebuah pengantar yang berisi tentang tokoh dan alur dari cerita game ini, lalu sebuah judul serta menu yang digunakan dalam game. Setelah itu menceritakan tugas sang pemain dalam menjalankan game ini. Apa yang akan dihadapi oleh pemain ditampilkan di dalan storyboard game ini.Berikut ini adalah Gambar dari desain storyboard game ini. 


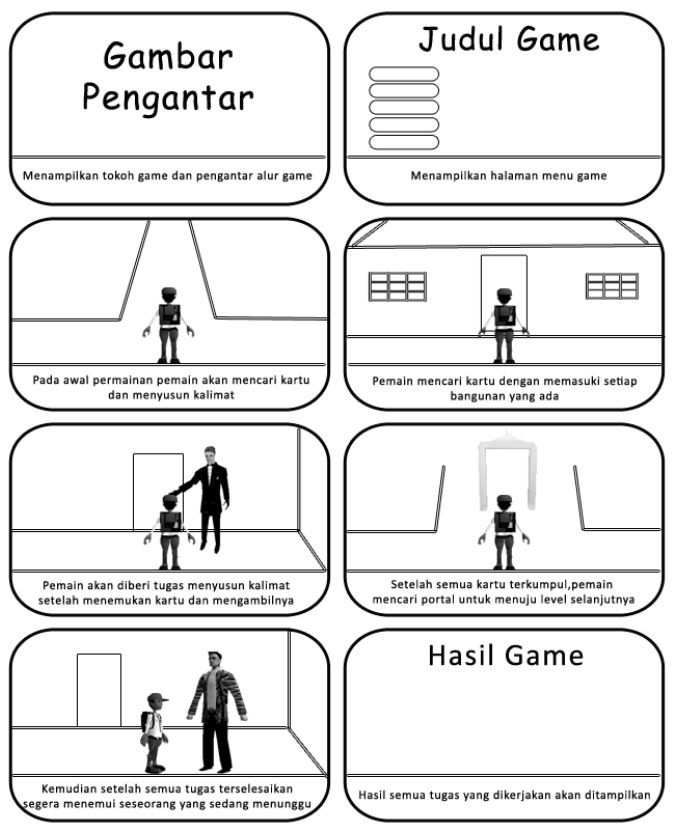

Gambar 3. Story Board Game

\subsection{DESAIN SISTEM}

Berikut adalah desain sistem secara umum yang akan dibangun dalam game.

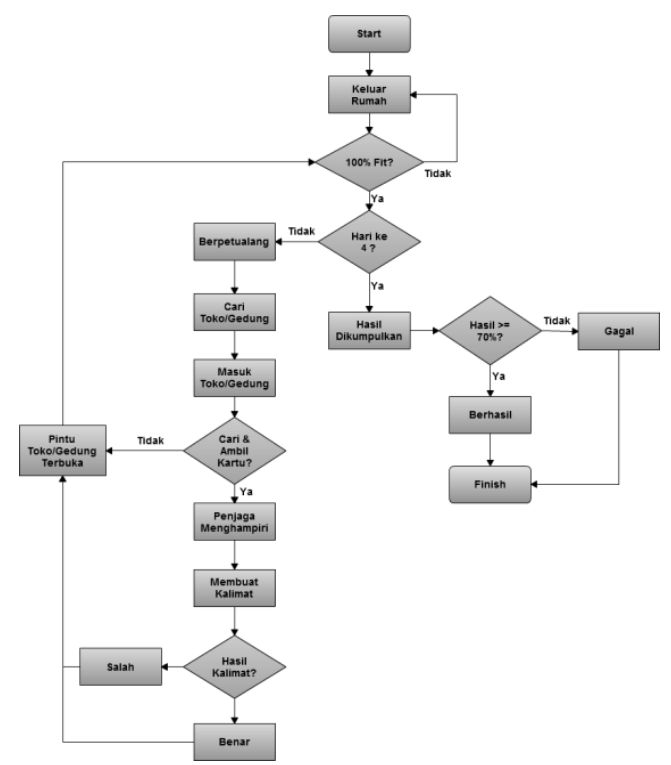

Gambar 4. Desain Sistem Game

\subsection{ALUR LEFT CORNER PARSING SEBAGAI} PEMERIKSA KALIMAT

Alur algoritma Left Corner Parsing yang akan digunakan untuk pemeriksaan jawaban dari susunan kata yang dimasukkan oleh pemain. Berikut adalah alur pemeriksaan tersebut.

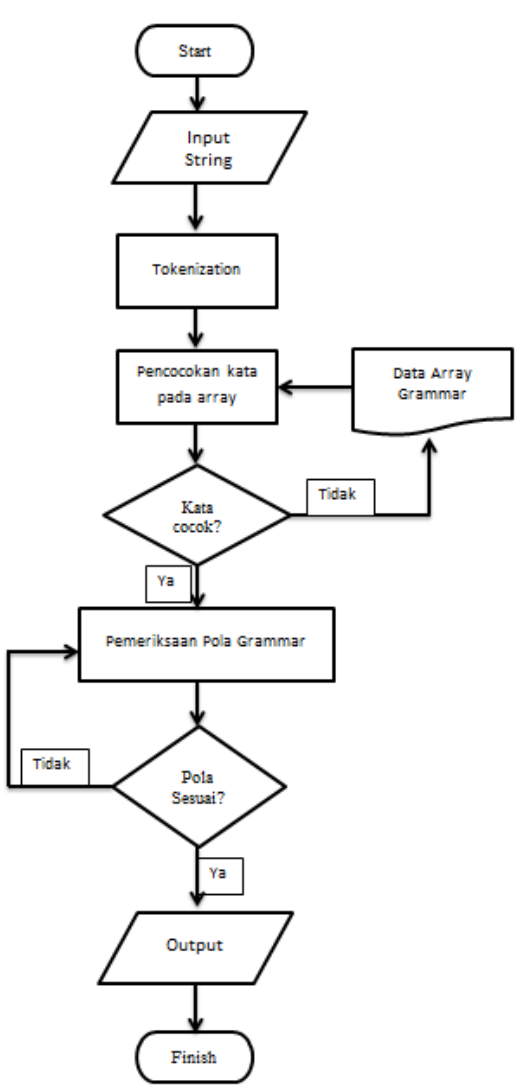

Gambar 5. Alur Pemeriksaan Left Corner Parsing

Proses pertama yaitu proses tokenization. Proses tokenization adalah tahap yang mengolah input menjadi kata atau karakter (Nayak \& Raghavan). Setelah menjadi kata atau karakter, proses selanjutnya mencocokkan dengan data yang berada dalam array. Apabila terjadi pencocokkan, langkah selanjutnya memeriksa setiap kata menggunakan aturan Left Corner Parsing. Aturan tersebut memeriksa setiap kata yang masuk dimana setiap kata tersebut memiliki jenis kata.

Kata pertama dalam aturan left corner sangat penting, karena menentukan kalimat tersebut benar atau salah melalui aturan pemeriksaan dari sisi kalimat paling kiri. Setelah mengetahui jenis kata yang dimiliki, kemudian mencocokkan dengan pola bangun kalimat yang telah ditentukan, bila sesuai pola, selanjutnya 
mencocokkan kata kedua dari input yang masuk. Seperti langkah dalam memeriksa kata pertama, begitupun proses langkah kedua. Pemeriksaan kata yang masuk berakhir ketika semua kata telah selesai diperiksa.

\section{HASIL DAN PEMBAHASAN 4.1 UJI COBA METODE}

Implementasi dari left corner parsing ini terdapat kelemahan yaitu dalam hal mengenal kata dan jenis kata yang ada. Sehingga yang seharusnya kalimat tersebut menurut pandangan seseorang tidak sesuai, akan tetapi memiliki pola grammar yang sama. Dilihat secara aturan dalam grammar, jawaban tersebut adalah benar. Hasil inputan juga dapat dipastikan di (http://www.grammarly.com)

bahwa kalimat tersebut juga dikenali dengan pola yang sama. Untuk lebih jelasnya dapat dilihat pada Tabel dibawah ini.

Tabel 2. Hasil Uji Coba Metode

\begin{tabular}{|c|l|l|l|}
\hline No & $\begin{array}{c}\text { Input } \\
\text { Kalimat }\end{array}$ & \multicolumn{1}{|c|}{ Pola } & \multicolumn{1}{|c|}{ Hasil } \\
\hline 1. & $\begin{array}{l}\text { My hat is } \\
\text { blue }\end{array}$ & $\begin{array}{l}\text { Pronoun- } \\
\text { noun-verb- } \\
\text { noun }\end{array}$ & $\begin{array}{l}\text { Kalimat } \\
\text { yang benar }\end{array}$ \\
\hline 2. & $\begin{array}{l}\text { My blue } \\
\text { is hat }\end{array}$ & $\begin{array}{l}\text { Pronoun- } \\
\text { noun-verb- } \\
\text { noun }\end{array}$ & $\begin{array}{l}\text { Blue dan hat } \\
\text { memiliki } \\
\text { jenis kata } \\
\text { yang sama, } \\
\text { Secara } \\
\text { pelafalan } \\
\text { kalimat } \\
\text { kurang tepat. }\end{array}$ \\
\hline 3. & $\begin{array}{l}\text { My } \\
\text { brother } \underline{\text { is }} \\
\text { sick }\end{array}$ & $\begin{array}{l}\text { Pronoun- } \\
\text { noun-verb- } \\
\text { verb }\end{array}$ & $\begin{array}{l}\text { Kalimat } \\
\text { yang benar }\end{array}$ \\
\hline 4. & $\begin{array}{l}\text { My } \\
\text { brother } \\
\text { sick is }\end{array}$ & $\begin{array}{l}\text { Pronoun- } \\
\text { noun-verb- } \\
\text { verb }\end{array}$ & $\begin{array}{l}\text { Sick dan is } \\
\text { mempunyai } \\
\text { sama pola. } \\
\text { Secara } \\
\text { pelafalan }\end{array}$ \\
\hline
\end{tabular}

\begin{tabular}{|c|c|c|c|}
\hline & & & kurang tepat. \\
\hline 5. & $\begin{array}{l}\text { Della } \\
\text { send me } \\
\text { a letter }\end{array}$ & $\begin{array}{l}\text { Noun- } \\
\text { verb-noun- } \\
\text { adjective- } \\
\text { noun }\end{array}$ & $\begin{array}{l}\text { Kalimat } \\
\text { yang benar }\end{array}$ \\
\hline 6. & $\begin{array}{l}\underline{\text { Letter }} \\
\text { send } \\
\underline{\text { Della a }} \\
\underline{\text { me }}\end{array}$ & $\begin{array}{l}\text { Noun- } \\
\text { verb-noun- } \\
\text { adjective- } \\
\text { noun }\end{array}$ & $\begin{array}{l}\text { Letter, } \\
\text { Della,dan } \\
\text { me } \\
\text { mempunyai } \\
\text { pola yang } \\
\text { sama. Secara } \\
\text { pelafalan } \\
\text { kalimat } \\
\text { kurang tepat. }\end{array}$ \\
\hline 7. & $\begin{array}{l}\text { Jakarta is } \\
\text { hot } \\
\text { weather }\end{array}$ & $\begin{array}{l}\text { Noun- } \\
\text { verb- } \\
\text { adjective- } \\
\text { noun }\end{array}$ & $\begin{array}{l}\text { Kalimat } \\
\text { yang benar }\end{array}$ \\
\hline 8. & $\begin{array}{l}\text { Weather } \\
\text { is hot } \\
\text { Jakarta }\end{array}$ & $\begin{array}{l}\text { Noun- } \\
\text { verb- } \\
\text { adjective- } \\
\text { noun }\end{array}$ & $\begin{array}{l}\text { Jakarta dan } \\
\text { weather } \\
\text { mempunyai } \\
\text { sama pola, } \\
\text { secara } \\
\text { pelafalan } \\
\text { kurang tepat }\end{array}$ \\
\hline 9. & $\begin{array}{l}\text { My } \\
\text { father } \\
\text { have two } \\
\underline{\text { cars }}\end{array}$ & $\begin{array}{l}\text { Pronoun- } \\
\text { noun-verb- } \\
\text { adjective- } \\
\text { noun }\end{array}$ & $\begin{array}{l}\text { Kalimat } \\
\text { yang benar }\end{array}$ \\
\hline 10. & $\begin{array}{l}\text { My cars } \\
\text { have two } \\
\text { father }\end{array}$ & $\begin{array}{l}\text { Pronoun- } \\
\text { noun-verb- } \\
\text { adjective- } \\
\text { noun }\end{array}$ & $\begin{array}{l}\text { Cars dan } \\
\text { father } \\
\text { mempunyai } \\
\text { sama pola, } \\
\text { secara } \\
\text { pelafalan } \\
\text { kurang tepat }\end{array}$ \\
\hline 11. & $\begin{array}{l}\text { I } \\
\text { canspeak } \\
\text { english } \\
\text { verywell }\end{array}$ & $\begin{array}{l}\text { Pronoun- } \\
\text { verb-verb- } \\
\text { noun- } \\
\text { adverb- } \\
\text { adverb }\end{array}$ & $\begin{array}{l}\text { Kalimat } \\
\text { yang benar }\end{array}$ \\
\hline 12. & $\begin{array}{l}\text { I } \\
\text { speakcan } \\
\text { english } \\
\text { very well }\end{array}$ & $\begin{array}{l}\text { Pronoun- } \\
\text { verb-verb- } \\
\text { noun- } \\
\text { adverb- }\end{array}$ & $\begin{array}{l}\text { Speak dan } \\
\text { can } \\
\text { mempunyai } \\
\text { sama pola, } \\
\text { secara }\end{array}$ \\
\hline
\end{tabular}




\begin{tabular}{|c|c|c|c|}
\hline & & adverb & $\begin{array}{l}\text { pelafalan } \\
\text { kurang tepat }\end{array}$ \\
\hline 13. & $\begin{array}{l}\text { I speak } \\
\text { can } \\
\text { english } \\
\text { wellvery }\end{array}$ & $\begin{array}{l}\text { Pronoun- } \\
\text { verb-verb- } \\
\text { noun- } \\
\text { adverb- } \\
\text { adverb }\end{array}$ & $\begin{array}{l}\text { Very dan } \\
\text { well } \\
\text { mempunyai } \\
\text { sama pola, } \\
\text { secara } \\
\text { pelafalan } \\
\text { kurang tepat }\end{array}$ \\
\hline 14. & $\begin{array}{l}\text { Malang } \\
\text { is cold } \\
\text { city }\end{array}$ & $\begin{array}{l}\text { Noun- } \\
\text { verb- } \\
\text { adjective- } \\
\text { noun }\end{array}$ & $\begin{array}{l}\text { Kalimat } \\
\text { yang benar }\end{array}$ \\
\hline 15. & $\begin{array}{l}\text { City is } \\
\text { cold } \\
\text { Malang }\end{array}$ & $\begin{array}{l}\text { Noun- } \\
\text { verb- } \\
\text { adjective- } \\
\text { noun }\end{array}$ & $\begin{array}{l}\text { Malang dan } \\
\text { city } \\
\text { mempunyai } \\
\text { sama pola, } \\
\text { secara } \\
\text { pelafalan } \\
\text { kurang tepat }\end{array}$ \\
\hline
\end{tabular}

Hasil masukan yang terdapat pada Tabel diatas membuktikan bahwa left corner parsing belum mampu mengenali kata yang mempunyai jenis kata yang sama. Left corner hanya melakukan pemeriksaan terhadap pola dari jenis kata yang dibangun. Sebagai contoh kalimat nomor 5 dan 6 . Kedua kalimat mempunyai pola yang sama, akan tetapi secara pelafalan atau pengucapan adalah salah.

\section{KESIMPULAN}

Hasil pengujian dalam menerapkan left corner parsing pada sebuah game adventure 3D yang telah dibangun dalam proses memeriksa sebuah susunan kata, menyimpulkan bahwa algoritma ini mampu mengenali pola grammar dengan baik, sehingga dapat digunakan untuk memeriksa kalimat tersebut sesuai pola yang dibentuk atau tidak, akan tetapi dilihat dari Tabel 2 untuk hal memilih kata yang cocok sesuai definisi yang dimiliki sebuah kalimat belum bisa, sehingga terdapat kalimat yang secara pola grammar dapat dikenali dan benar, akan tetapi secara pelafalan dirasa kurang tepat.

Dalam hasil uji coba kepada 20 responden anak-anak yang berumur antara 8 sampai 13 tahun, dapat disimpulkan bahwa game "Go to London Adventure" ini menyenangkan dan menarik bagi responden, terbukti total keseluruhan responden tertarik terhadap game yang dibuat, yaitu dengan nilai prosentase sebesar $97 \%$.

\section{DAFTAR PUSTAKA}

1) Abdurohman, M., Hadi, S., \& Rohidin, D. (2006). Pemeriksaan Tata Bahasa Dalam Kalimat Bahasa Inggris Menggunakan Algoritma Left Corner Parsing. Seminar Ilmiah Nasional Komputer dan Sistem Intelijen (KOMMIT 2006), (hal. 76-82). Depok.

2) Greenbaum, S. (1996). English Grammar. Oxford University Press.

3) Hidayat, R. T. (2006). Belajar Mudah Bahasa Inggris. Yogyakarta: PUSTAKA PELAJAR.

4) http://www.grammarly.com.

5) Nasution, S. H., Widiastuti, W. L., \& Pasaribu, S. M. (1985). Petunjuk Pemrograman C Edisi Kedua. Jakarta: Erlangga.

6) Nina, A. R. (2010). English Grammar. Yogyakarta: Pustaka Widiatama.

7) Priyana, D. (2013, Maret 19). Pentingnya ber-Bahasa Inggris. (D. Priyana, Penyunting) Dipetik Mei 16, 2013, dari Azzahra News: http://news.universitasazzahra.ac .id/pentingnya-ber-bahasainggris/ 
8) Sibero, I. C. (2009). Langkah Mudah Membuat Game 3D. Yogyakarta: MediaKom.

9) Suciadi, J. (2001). STUDI ANALISIS METODEMETODE PARSING DAN INTERPRETASI SEMANTIK PADA NATURAL LANGUAGE. JURNAL INFORMATIKA, II(1), 13-22.

10) Winarno, E. D. (2006). Belajar Tuntas Tata Bahasa Inggris (Tanpa Guru). Yogyakarta: PUSTAKA PELAJAR. 